\title{
A placebo-controlled trial of isoprinosine in patients with multiple sclerosis
}

\author{
N M Milligan, D H Miller, D A S Compston
}

\begin{abstract}
Isoprinosine was used under doubleblind, randomised, and placebocontrolled conditions in 52 patients with relapsing/remitting or progressive multiple sclerosis. All patients received pulsed treatment with methylprednisolone. There was no significant effect of treatment on clinical disability or the accumulation of MRI abnormalities, after correction of results for multiple comparisons. It is concluded that isoprinosine is not effective therapy for multiple sclerosis.
\end{abstract}

(F Neurol Neurosurg Psychiatry 1994;57:164-168)

Despite steady progress in understanding the pathogenesis of multiple sclerosis, treatment that influences the long-term course of the disease has yet to be identified. Pulsed, highdose, intravenous methylprednisolone is now used widely in the management of acute relapse and also improves disability arising from spasticity in some patients with chronic progressive disease. ${ }^{2}$ The consensus view on the use of currently available immunosuppressive treatments is that these are not effective or, at best, stabilise the rate of accumulation of disability after a delay of many months. Statistically significant results have been reported after long-term treatment but the therapeutic benefits are rarely useful for the individual patient. Most of these treatments carry significant adverse effects.

In the study reported here and in previous trials, ${ }^{3}$ the use of pulsed, intravenous methylprednisolone was followed by long-term oral immunological therapy in an attempt to achieve rapid and sustained clinical improvements. Isoprinosine was selected for oral therapy because, during the design phase, this was considered to be effective in several tissue specific disorders characterised by an inappropriate immune response. Isoprinosine is remarkably free from adverse effects ${ }^{45}$ and preliminary evidence suggested a beneficial role in the treatment of multiple sclerosis. ${ }^{6-9}$

Intravenous methylprednisolone was given electively to all patients at the start of the study. Participants were then randomised to receive oral isoprinosine under double-blind and placebo-controlled conditions. Clinical outcome measures (relapse frequency, expanded disability status, and ambulation index) were supplemented by quantitative MRI. This preliminary study was limited to about 50 participants, given the relative lack of clinical information relating to the use of isoprinosine in multiple sclerosis.

\section{Materials and methods}

PATIENTS

A population-based register of patients with multiple sclerosis was used to identify patients suitable for inclusion in the study. A total of 104 patients, with scores on 1 January 1986 of $<5.5$ on the Kurtzke expanded disability status scale (EDSS) ${ }^{10}$ were invited to discuss participation in the trial. Each patient had been classified with the Poser criteria ${ }^{11}$ and had clinically definite or laboratory supported probable disease. Eighty-three were later interviewed and examined. Twentyeight were not willing to take part or were considered unsuitable because at review the clinical manifestations were negligible or had become too severe for inclusion in the study. Despite this precaution, a number of recruited patients subsequently deteriorated and had a Kurtzke EDSS of $>5.5$ at the time of entry. The trial protocol was described verbally and in writing to each participant who signed a statement of consent. Fifty-four patients entered the study but two were subsequently withdrawn because of failure to follow the agreed protocol. Three others completed most of the trial but were lost to follow up at two years. One discontinued treatment because of pregnancy.

\section{METHODS}

All participants were reassessed by one clinician (NMM) who carried out a standard neurological examination at entry. Details of the clinical history were used to classify patients as having relapsing/remitting $(n=26)$ or chronic progressive $(n=26)$ disease. Of the 26 chronic progressive cases, four had primary and 22 secondary progressive disease. Based on physical signs, scores were obtained in all cases for the Kurtzke EDSS ${ }^{10}$ and the (Hauser) ambulation index. ${ }^{12}$ On one of the next two days (day 2 or 3 ) each patient underwent brain MRI on a 0.5 Tesla system provided by the Multiple Sclerosis Society of Great Britain and Northern Ireland at the National Hospital, Queen Square, London. Axial, contiguous $5 \mathrm{~mm}$ thick slices through the whole brain were obtained with a moderately T2-weighted sequence $\left(\mathrm{SE}_{2000 / 60}\right)$. Participants received $0.5 \mathrm{~g}$ methylprednisolone by intravenous infusion over 30 minutes in saline, as previously described, ${ }^{1}$ between 
days $6-10$, on an outpatient basis. A second assessment of clinical status, including EDSS score and ambulation index, was performed on day 14. Each patient was randomised, irrespective of clinical course, to take oral isoprinosine ( $3 \mathrm{~g}$ daily) in divided doses or a placebo preparation containing lactose, prepared and distributed by the same manufacturers. A second MRI scan was performed on day 16 or 17 and patients started treatment on day 20 for the duration of the trial (two years). Clinical assessments were made at intervals of four months (that is, on six further occasions) and any new relapses, adverse drug effects, or coincidental illnesses were recorded. After two years of oral therapy with isoprinosine or placebo, patients had a final clinical assessment and a third MRI scan. Blood pressure, weight, and urinalysis were recorded at each visit together with routine haematological and biochemical assessments, including measurement of blood urate. At the end of the study, the second and third MRI scans were reviewed by two neuroradiologists who recorded and compared all changes by consensus. Each was blind with respect to the clinical outcome and randomisation to active or placebo treatment.

\section{STATISTICS}

Mean age and baseline disability scores were compared by $t$ tests. The distributions for duration of disease and ambulation index were skewed and are therefore described as medians, which were compared with the nonparametric Mann-Whitney test. This test was also used to compare median numbers of new or enlarged and disappeared or decreased lesions demonstrated by MRI. The results of treatment were compared between groups by analysis of covariance with disability score at each follow-up point as outcome and baseline assessment as covariate. Tests of significance were corrected for multiple comparisons.

\section{Results}

CHARACTERISTICS AT ENTRY

Fifty-two patients completed the study; two patients withdrew before starting oral treatment with isoprinosine or placebo and were not included in the analysis. One patient stopped oral therapy after becoming pregnant, but her assessments continued for two years. Two patients were lost to follow up during the study. These three cases have been included in the analysis of results.

Table 1 Baseline characteristics of patients at entry into the trial

\begin{tabular}{ccccll}
\hline & $\begin{array}{l}\text { No of } \\
\text { patients }\end{array}$ & $\begin{array}{l}\text { Age } \\
(y)\end{array}$ & $\begin{array}{l}\text { Duration } \\
(y)\end{array}$ & $\begin{array}{l}\text { Disability } \\
\text { (Kurtzke EDSS) }\end{array}$ & $\begin{array}{l}\text { Ambulation index } \\
\text { (Hauser) }\end{array}$ \\
\hline Isoprinosine: & & & & & \\
All patients & 25 & 38.4 & 7 & 2.6 & $2 \cdot 0$ \\
Relapsing & 17 & 36.4 & 7 & $2 \cdot 2$ & 1.0 \\
Progressive & 8 & 42.6 & 11.5 & 3.6 & 2.5 \\
Placebo: & & & & & \\
All patients & 27 & 42.7 & 8 & 3.2 & 2.0 \\
Relapsing & 9 & 43.1 & 10 & 2.3 & 1.5 \\
Progressive & 18 & 42.5 & 7 & 3.6 & 2.0 \\
\hline
\end{tabular}

Twenty five patients were randomised to active treatment with isoprinosine and 27 received placebo preparations. There were no significant differences between these groups in age, duration of disease, Kurtzke EDSS, or ambulation index at entry (table 1). An equal number of relapsing/remitting (26) and chronic progressive (26; four primary and 22 secondary progressive) cases were studied but, due to a randomisation error, more patients in the isoprinosine-treated $(17 / 25)$ than placebo (9/27) group had relapsing/ remitting disease. Conversely, there was an excess of cases treated with placebo (18/26) compared with those treated with isoprinosine $(8 / 26)$ in the chronic progressive group. Mean age was significantly higher in the isoprinosine-treated cases with relapsing/ remitting disease but, in all other respects, there were no baseline differences between patients actively treated or given placebo. The relapsing and chronic progressive patients were comparable with respect to age and duration of illness. It followed that, as a group, the chronic progressive cases were more disabled than relapsing patients at entry.

\section{DISABILITY}

Considering all subjects, there was no significant difference in disability scores between the treated and control groups at $16,32,64$, 80 , and 96 weeks. There was an effect in favour of isoprinosine treatment compared with the placebo group at 48 weeks $(t=2 \cdot 08$; $\left.p=0.043 ; p_{c}=0.30\right)$. No significant differences in disability between patients treated with isoprinosine and placebo were seen when the subgroup of relapsing/remitting patients was separately analysed. There was a significant effect in favour of treatment with isoprinosine in chronic progressive cases at one week $\left(t=2.33 ; \mathrm{p}<0.029 ; \mathrm{p}_{\mathrm{c}}=0.20\right)$ but not at any subsequent follow up point. Because of the non-random distribution of cases treated with isoprinosine and placebo with respect to clinical course, and the effect this had on baseline disability, the actively treated patients remained clinically less disabled throughout the period of follow up. As a group, their clinical course was stable until 48 weeks when there was a slight increase in disability. By contrast, the patients treated with placebo were consistently more disabled and had deteriorated considerably after 64 weeks.

The effects of active and placebo treatments were also compared in terms of the number of patients whose disability scores increased or decreased during the study. There was no significant difference between the two groups of relapsing/remitting patients but a greater proportion of placebo than actively treated progressive cases showed an increase in disability during the trial. This effect was also seen when the results were compared between all patients receiving isoprinosine and those receiving placebo, analysed without respect to clinical course. Taken with the analysis of covariance, this 
Table 2 Number of patients in each category deteriorating or improved at completion of the trial

\begin{tabular}{|c|c|c|c|c|c|}
\hline & \multirow{2}{*}{$\begin{array}{l}\text { No of } \\
\text { patients }\end{array}$} & \multicolumn{2}{|l|}{ Disability } & \multicolumn{2}{|c|}{ Ambulation index } \\
\hline & & Decreased & Increased & Decreased & Increased \\
\hline $\begin{array}{c}\text { Isoprinosine: } \\
\text { All patients } \\
\text { Relapsing } \\
\text { Progressive }\end{array}$ & $\begin{array}{r}25 \\
17 \\
8\end{array}$ & $\begin{array}{l}7 / 23^{\star} \\
6 / 16 \\
1 / 7\end{array}$ & $\begin{array}{l}5 / 23 \\
4 / 16 \\
1 / 7\end{array}$ & $\begin{array}{l}1 / 23 \\
1 / 16 \\
1 / 7\end{array}$ & $\begin{array}{l}5 / 23 \\
3 / 16 \\
2 / 7\end{array}$ \\
\hline $\begin{array}{l}\text { Placebo: } \\
\text { All patients } \\
\text { Relapsing } \\
\text { Progressive }\end{array}$ & $\begin{array}{r}27 \\
9 \\
18\end{array}$ & $\begin{array}{l}8 / 27 \\
5 / 9 \\
3 / 18\end{array}$ & $\begin{array}{c}13 / 27 \\
2 / 9 \\
11 / 18\end{array}$ & $\begin{array}{l}2 / 25 \\
2 / 8 \\
1 / 17\end{array}$ & $\begin{array}{c}12 / 25 \\
4 / 8 \\
8 / 17\end{array}$ \\
\hline
\end{tabular}

* Two patients were lost to follow up and do not appear in the final results for treated patients.

Table 3 Number of patients reporting new relapses during the trial

\begin{tabular}{|c|c|c|c|c|c|c|}
\hline & \multirow{2}{*}{$\begin{array}{l}\text { No } \\
\text { of patients }\end{array}$} & \multicolumn{5}{|c|}{ Relapses } \\
\hline & & 0 & 1 & 2 & 3 & 4 \\
\hline $\begin{array}{l}\text { Isoprinosine: } \\
\text { All patients } \\
\text { Relapsing } \\
\text { Progressive }\end{array}$ & $\begin{array}{r}25 \\
17 \\
8\end{array}$ & $\begin{array}{r}12 \\
6 \\
6\end{array}$ & $\begin{array}{l}7 \\
6 \\
1\end{array}$ & $\begin{array}{l}4 \\
3 \\
1\end{array}$ & $\begin{array}{l}0 \\
0 \\
0\end{array}$ & $\begin{array}{l}2 \\
2 \\
0\end{array}$ \\
\hline $\begin{array}{l}\text { Placebo: } \\
\text { All patients } \\
\text { Relapsing } \\
\text { Progressive }\end{array}$ & $\begin{array}{r}27 \\
9 \\
18\end{array}$ & $\begin{array}{r}13 \\
11 \\
2\end{array}$ & $\begin{array}{r}11 \\
4 \\
7\end{array}$ & $\begin{array}{l}1 \\
1 \\
0\end{array}$ & $\begin{array}{l}1 \\
1 \\
0\end{array}$ & $\begin{array}{l}1 \\
1 \\
0\end{array}$ \\
\hline
\end{tabular}

effect of treatment was not considered to be statistically significant.

\section{AMBULATION INDEX}

Changes in the ambulation index seemed to show a significant effect in favour of active treatment although this partly arose from the trend towards lower baseline ambulation indices in patients receiving isoprinosine. This effect was compounded by the randomisation error resulting in a significant difference in the number of relapsing/remitting and chronic progressive patients receiving active and placebo therapy. When median ambulation indices were compared separately in the relapsing/remitting and chronic progressive cases, there was no significant difference in either group at any follow-up point except for the relapsing/remitting patients at 16 weeks $\left(\mathrm{p}=0.028 ; \mathrm{p}_{\mathrm{c}}=0.19\right)$.

Active and placebo treatment has also been compared by identifying patients whose ambulation index increased or decreased during the study. There was a trend towards a more favourable course in all patients receiving isoprinosine, and in the sub-group of progressive cases, which was not seen in the relapsing/remitting group (table 2 ).

Table 4 Number of patients showing MRI changes during the trial

\begin{tabular}{llll}
\hline & & New or enlarged & Decreased or gone \\
\cline { 3 - 4 } & No of patients & Total number of lesions \\
\hline Isoprinosine: & & & \\
All patients & 20 & $15(127)$ & $13(34)$ \\
$\quad$ Relapsing & 14 & $10(106)$ & $10(16)$ \\
Progressive & 6 & $5(21)$ & $3(18)$ \\
Placebo: & & & \\
All patients & 25 & $19(113)$ & $14(35)$ \\
$\quad$ Relapsing & 8 & $7(35)$ & $6(17)$ \\
Progressive & 17 & $12(78)$ & $8(18)$ \\
\hline
\end{tabular}

RELAPSES

Twenty three new relapses were reported by the 25 patients receiving isoprinosine compared with 20 by the 27 patients-receiving placebo (table 3); two patients in each group had more than three relapses during the trial. A disproportionate number of patients receiving isoprinosine had relapsing/remitting disease and these would therefore be expected to have had more relaspes than patients treated with placebo, more of whom had entered the chronic progressive phase. The relapse frequency was similar, however, in both groups despite this randomisation bias.

MRI

Forty five patients underwent MRI before and immediately after treatment with methylprednisolone, and on completion of the trial. Three had primary progressive, 23 secondary progressive, and 19 relapsing/remitting disease. Comparisons were made between the number of new or enlarged lesions and those that decreased in size or disappeared between the second and third scan (table 4). The median number of lesions did not differ between all treated patients compared with controls, or in the subgroups with relapsing/ remitting and chronic progressive disease. Two patients treated with isoprinosine acquired 24 and 26 new lesions during the trial, respectively; the largest number acquired by any patient receiving placebo was 14. One patient receiving active treatment had 15 lesions that decreased in size or disappeared; the largest number of improving lesions in any patient randomised to placebo treatment was eight. Eleven patients treated with isoprinosine showed both an increase and decrease in MRI lesions during the trial compared with 10 patients randomised to placebo treatment. The two patients who accumulated most new or enlarged lesions each improved clinically by half a step on the Kurtzke EDSS. One remained normal on the ambulation index and the other improved by one step; each had one clinical relapse during the two year period of observation. The actively treated patient in whom $15 \mathrm{MRI}$ lesions decreased or disappeared, deteriorated by 2.5 steps on the Kurtzke EDSS but ambulation improved by one point and she had a single relapse. The patient treated with placebo who had eight improving lesions remained clinically unchanged on completion of the study, even though two relapses occurred during the trial.

\section{ADVERSE EFFECTS}

Thirteen patients in the group receiving isoprinosine reported adverse effects compared with eight placebo-treated cases. Overall, there was no difference in the frequency or type of complication reported by each group; in no case was treatment withdrawn and the adverse effects usually settled spontaneously suggesting that they were not causally related to treatment. Adverse effects included skin rash (five: all active cases), diarrhoea (one in each group), anorexia (two in each group), 
alopecia (one active case), mouth ulcers (one active case), anaemia (one active case), nausea (one active case), abdominal pain (five placebo cases), and multiple unclassifiable complaints (one active case).

\section{Discussion}

Isoprinosine given under double-blind and placebo-controlled conditions after pulsed treatment with methylprednisolone did not influence clinical disability or the rate of accumulation of lesions found by brain MRI in patients with multiple sclerosis.

Isoprinosine is a physicochemical complex of inosine with the para-acetamidobenzoic acid salt of N,N-dimethylamino-2-propanolol that enhances B lymphocyte activity, perhaps through an effect on $\mathrm{T}$ helper cells. It also increases macrophage phagocytosis, release of cytokines which induce macrophage proliferation including immune interferon and interleukins 1 and 2 , and augments the action of $\mathrm{T}$ cell mitogens. ${ }^{451314}$ Modest success has been reported in diseases in which immune reactions are thought to complicate viral infection. There is a very low frequency of adverse effects attributable to treatment with isoprinosine. Neurological diseases that have been studied include subacute sclerosing panencephalitis, ${ }^{15-18}$ progressive rubella encephalitis $^{19}$ and other encephalitides, ${ }^{20}$ amyotrophic lateral sclerosis, ${ }^{21}$ multiple sclerosis, ${ }^{6-9}$ and experimental allergic encephalomyelitis. $^{22}$ Isoprinosine has been used in organ specific inflammatory diseases such as rheumatoid arthritis, ${ }^{2324}$ and in AIDS. ${ }^{25} 26$

Pompidou et $a l^{7}$ compared the clinical and immunological effects of isoprinosine, chlorambucil, and a placebo preparation in a small cohort of patients with multiple sclerosis over 2 years. A higher dose of isoprinosine was used than in the present study and this makes it difficult to compare the results directly. Relapses occurred in each patient treated with chlorambucil or placebo preparations but in only a few patients receiving isoprinosine. These relapses did not differ in severity between the three groups but the authors reported a reduction in handicap associated with the use of isoprinosine. Immunological studies showed increased suppressor cell number and function in cases treated with isoprinosine, whereas cells with the $T$ helper phenotype and delayed type hypersensitivity were reduced in patients receiving chlorambucil.

Multiple sclerosis has attracted many different approaches to treatment. In most studies, the effect of therapy has been so small as to require more participants than could easily be recruited by an individual investigator. This has led to the development of multicentre trials and meta-analyses, ${ }^{27-31}$ each of which combines strength in numbers with potential variations in methodology, selection of cases, and the application of research protocols. Perhaps the greatest barrier to progress has been extravagant reporting of results leading to a decline in the acceptability of placebo-controlled trials and the need for increasingly complex designs to control for simultaneous use of several treatments. Failure to identify a treatment that is genuinely useful may also occur through inadequate trial design. To some extent these issues are being resolved by the use of surrogate outcome measures, including quantitative MRI. ${ }^{29}$

Although only planned as a preliminary study, this trial of isoprinosine in the treatment of multiple sclerosis committed a number of these design faults. Fewer than 30 patients were included in each group, two therapies were used sequentially, and the active and placebo groups were not matched at entry. This produced differences in baseline scores that contaminated a number of comparisons made at follow up. As stabilisation or a reduction in clinical disease activity is more likely to be observed in mildly affected than severe cases, however, this randomisation error will, if anything, have tended to overestimate the efficacy of isoprinosine. As no overall effect was found with four outcome measures, we conclude that isoprinosine is not an effective treatment for multiple sclerosis.

Current ideas on the immunopathogenesis of multiple sclerosis, and the lack of progress in showing persistent viral infection as central to this disease process, provide little support for the continued use of treatments that stimulate $B$ or $T$ cell mediated immune responses. ${ }^{33}$ Priority should be given to theoretically more promising approaches ${ }^{3435}$ in using the increasingly limited clinical and research resources that remain available for trials in multiple sclerosis. ${ }^{36}$

We thank Dr B E Kendall and Dr I F Moseley for reporting the MRI scans; these were performed by Mr D MacManus. Dr B Youl assisted in the MRI analysis. We are grateful to Mr $S$ E Roberts and Dr R G Newcombe, University of Wales College of Medicine, Heath Park, Cardiff, who carried out the statistical analysis. Isoprinosine was supplied by the Laboratories Ltd, Aylesbury, Buckinghamshire, and we are grateful to Dr A P Menday for assistance in organising the study.

1 Milligan NM, Newcombe RG, Compston DAS. A double blind-controlled trial of high dose methylprednisolone in patients with multiple sclerosis. $\mathcal{f}$ Neurol Neurosurg Psychiatry 1987;50:511-6.

2 Thompson AJ, Kennard C, Swash M, Summers B, Yuill GM, Shepherd DI, et al. Relative efficacy of intravenous methylprednisolone and ACTH in the treatment of methylprednisolone and ACTH in the treatm
acute relapse in MS. Neurology 1989;39:969-71.

3 Ellison GW, Myers LW, Mickey MR, Graves MC Tourtellotte WW, Syndulko K, et al. A placebo-
Who , controlled, randomised, double-masked, variable dosage, clinical trial of azathioprine with and without methylprednisolone in multiple sclerosis. Neurology 1989;39:1018-26.

4 Campoli-Richards DM, Sorkin EM, Heel RC. Inosine pranobex. A preliminary review of its pharmacokinetic properties and therapeutic efficacy. Drugs 1986;32. 383-424.

5 Hadden JW, Speafico F. New strategies of immunotherapy. Springer Semin Immunopathol 1985;8:139-52.

6 Pompidou A, Rancurel G, Delsaux MC, Telve L, Cour V. Clinical and immunological improvement of active multiple sclerosis by isoprinosine treatment. A randomised pilot study. Presse Med 1986;15:930-1.

7 Pompidou A, Rancurel G, Delsaux M-C, et al. Immunosuppressive effects of isoprinosine in man: a comparison to chlorambucil effects in multiple sclerosis. Cancer to chlorambucil effects in multiple

8 Caltagirone C, Carlesimo A. Methisoprinol in the treatment of multiple sclerosis. Acta Neurol Scand 1986;74: 293-6.

9 Maciejek Z. Changes in visual evoked potentials in 
patients with multiple sclerosis treated with isoprinosine and amantadine. Arch Immunol Ther Exp (Warsz) 1989; 37:621-8

10 Kurtzke JF. Rating neurologic impairment in multiple sclerosis. An expanded disability status scale (EDSS). Neurology 1983;33:1444-52.

11 Poser CM, Paty DW, Scheinberg L, et al. New diagnostic criteria for multiple sclerosis; guidelines for research protocols. Ann Neurol 1983;13:227-31.

12 Hauser SL, Dawson DM, Lehrich JR, et al. Intensive immunosuppression in progressive multiple sclerosis. N Engl f Med 1983;308:173-80.

13 Nakamura T, Miyasaka N, Pope RM, Talal N, Russell IJ. Immunomodulation by isoprinosine: effects on in vitro immune functions of lymphocytes from humans with autoimmune diseases. Clin Exp Immunol 1983;52: with autoi.

14 Fischbach $M$, Talal N. Ability of isoprinosine to restore interleukin-2 production and $T$ cell proliferation in autoimmune mice. Clin Exp Immunol 1985;61:242-7.

15 Silverberg R, Brenner T, Abramsky O. Inosiplex in the treatment of subacute sclerosing panencephalitis. Arch Neurol 1979;36:374-5

16 Jones CE, Dyken PR, Huttenlocher PR, Jabbour JT, Maxwell KW. Inosiplex therapy in subacute sclerosing panencephalitis. Lancet 1982;i:1034-7.

17 Dyken PR, Swift A, DuRhant RH. Long term followup of patients with subacute sclerosing panencephalitis treated with inosiplex. Ann Neurol 1982;11: 359-64.

18 Moodley M, Moosa A. Subacute sclerosing panencephalitis in black children-a review of 18 cases. $Q f$ Med alitis in black ch

19 Wolinsky JS, Dau PC, Buimovici-Klein D, Mednick J, Berg BO. Progressive rubella panencephalitis: immunovirological studies and results of isoprinosine therapy. Clin Exp Immunol 1979;2:397-404.

20 Buge A, Rancurel G, Metzger J, Picard A, Lesourd B, Gardeur $D$. Isoprinosine in treatment of acute viral encephalitis. Lancet 1979;ii:691.

21 Brody JA, Chen KM, Yase Y, Holdern EM, Morris CE. Inosiplex and amyotrophic lateral sclerosis. Arch Neurol 1974;30:322-3.

22 Bisteau M, Devos G, Brucher JM, Gonsette RE. Prevention of subacute experimental allergic encephalomyelitis in guinea pigs with desferrioxamine, isoprinosine and in guinea pigs with desferrioxamine, isoprinosine and mitaxanthrone. In: Gonsette RE, Delmotte P, eds. Recent advances in multiple sclerosis

23 Brzeski M, Madhok R, Hunter JA, Capell HA. Randomised, double-blind, placebo controlled trial of isosine pranobex in rheumatoid arthritis. Ann Rheum Dis 1990;49:293-5.
24 Bonvoisin B, Sidot C, Touraine JL, Touraine F, Bouvier $M$. Moderate efficacy of isoprinosine as a therapy for rheumatoid arthritis. Clin Exp Rheumatol 1983;i: 279-80.

25 Pedersen C, Sandstrom E, Petersen CS, et al. The efficacy of isoprinosine pranobex in preventing the acquired immunodeficiency syndrome in patients with human immunodeficiency virus infection. $N$ Engl f Med 1990; 322:1757-63.

26 Tsang KW, Fudenberg HH, Galbraith GMP, Donnelly RP, Bishop LR, Koopman WR. Partial restoration of impaired interleukin-2 production and Tac antigen (putative interleukin-2 receptor) expression in patients with acquired immune deficiency syndrome by isoprinowine treatment in vitro. $¥$ Clin Invest 1985;75:1538-44.

27 Yudkin PL, Ellison GW, Ghezzi A, et al. Overview of azathioprine treatment in multiple sclerosis. Lancet azathioprine trea

28 Canadian Cooperative Multiple Sclerosis Study Group. The Canadian cooperative trial of cyclophosphamide and plasma exchange in progressive multiple sclerosis. Lancet 1991;337:441-6.

29 Kappos L, Patzold U, Dommasch D, et al. Cyclosporine vs. azathioprine in the long term treatment of mutiple sclerosis-results of the German multicentre study. Ann Neurol 1988;23:56-63.

30 Multiple Sclerosis Study Group. Efficacy and toxicity of cyclosporine in chronic progressive multiple sclerosis: a randomised, double blinded, placebo controlled clinical randomised, double blinded, place
trial. Ann Neurol 1990;27:591-605.

31 Rudge PR, Koetsier JC, Mertin J, et al. Randomised double blind controlled trial of cyclosporin in multiple double blind controlled trial of cyclosporin in multiple

32 Miller DH, Barkhof F, Berry I, Kappos L, Scotti G, Thompson AJ. Magnetic resonance imaging in monitoring the treatment of multiple sclerosis. $f$ Neurol Neurosurg Psychiatry 1991;54:683-8.

33 Panitch HS, Hirsch RL, Haley AS, Johnson KP. Exacerbations of multiple sclerosis in patients treated with gamma interferon. Lancet 1987;i:893-5.

34 The IFNB Multiple Sclerosis Study Group. Interferon beta-1b is effective in relapsing-remitting multiple sclerosis. 1. Clinical results of a multicenter, randomized, double-blind, placebo-controlled trial. Neurology 1993;43:655-61.

35 Paty DW, Li DKB. The IFNB Multiple Sclerosis Study Group. Interferon beta-1b is effective in relapsing-
remitting multiple sclerosis. MRI results of a multiremitting multiple sclerosis. MRI results of a multicenter, randomized, double-blin
trial. Neurology 1993;43:662-7.

36 Compston DAS. Limiting and repairing the damage in multiple sclerosis. F Neurol, Neurosurg Psychiatry 1991; 54:945-8 